\title{
Optimal measurement strategies for aboveground tree biomass in agricultural landscapes
}

\author{
Shem Kuyah • Todd S. Rosenstock
}

Received: 20 March 2014/Accepted: 10 September 2014/Published online: 19 September 2014

(C) The Author(s) 2014. This article is published with open access at Springerlink.com

\begin{abstract}
Robust and cost effective methods for estimating aboveground biomass of trees on farms are necessary to understand the significance of this carbon pool, identify climate change mitigation opportunities and support smallholder farmers' ability to capitalize on the emerging green economy. Using a dataset of 72 destructively sampled trees and 855 non-destructively sampled trees, we identified methodologically and economically efficient strategies to construct allometric equations and measure on-farm tree biomass. We found that robust biomass estimates can be obtained from measuring diameter at breast height (DBH) alone. Inclusion of tree height, specific wood density, and/or crown area in the allometric equation changed the biomass estimates by only $1.3 \%$, though these additional variables improved precision by reducing the error from $7.8 \%$ to between 4.8 and $7.0 \%$. Research accuracy-to-cost trade-offs can be optimized by building equations based on destructive
\end{abstract}

Electronic supplementary material The online version of this article (doi:10.1007/s10457-014-9747-9) contains supplementary material, which is available to authorized users.

S. Kuyah $(\bowtie)$

Jomo Kenyatta University of Agriculture and Technology

(JKUAT), P.O. Box 62000, Nairobi 00200, Kenya

e-mail: s.kuyah@cgiar.org; kuyashem@gmail.com

T. S. Rosenstock

World Agroforestry Centre (ICRAF),

P.O. Box 30677, Nairobi 00100, Kenya measurements of trees that span stem diameters found in the landscape; equations based on only small or large diameter trees result in poor estimates. Given (1) the resources required to measure additional dendrometric parameters in the field (2) the potential to introduce measurement errors that can propagate through estimates at farm and landscape scales, and (3) the need to quickly increase the amount of data available at low cost, we recommend that allometric equations for trees on farms be based solely on DBH and that the sampling strategy capture the range of tree sizes found in the landscape and future indirect quantification should focus on diameter at breast height as a predictor of biomass to save resources.

Keywords Agricultural ecosystems - Allometric equations $\cdot$ Carbon stocks $\cdot$ Tree biomass $\cdot$ Western Kenya

\section{Introduction}

Trees are a critical component of the global carbon (C) cycle. Forests account for $45 \%$ of terrestrial carbon stocks and deforestation is responsible for $17 \%$ of annual radiative forcing (IPCC 2007). Carbon quantification efforts typically take a forest-centric perspective ignoring trees outside of forest boundaries. However, more than $45 \%$ of farmland globally has $10 \%$ or greater tree-cover (Zomer et al. 2009) and 
C stocks in the biomass of these system ranges between $3-18 \mathrm{Mg} \mathrm{C}^{-1}$ (Nair and Nair 2014). Although the aboveground $\mathrm{C}$ stocks found in trees on farms are less than forests, the aggregate $\mathrm{C}$ pool is presumably significant due to the spatial extent of farmland with some tree cover (Zomer et al. 2009). Furthermore, increasing the area and density of trees on farm accumulates more $\mathrm{C}$ in biomass and is an important climate change mitigation strategy (Verchot et al. 2007; Lal 2004), especially when it is done in a way that can reduce competition and enhance complementarity between trees and crops. Despite the importance of the $\mathrm{C}$ in trees, there is a paucity of data on $\mathrm{C}$ and biomass stored in trees on farms (de Foresta et al. 2013). This research aims to establish costeffective and robust approach for monitoring $\mathrm{C}$ stocks in trees on farms.

Estimating biomass of trees on farmland presents unique challenges. Trees on farms typically show greater phenotypic plasticity than trees inside of forests. Human management such pruning and fertilization and heterogeneous growing conditions can change light and nutrient availability to produce unpredictable tree architecture (Harja et al. 2012). These irregular tree geometries may render available allometric equations and data irrelevant because allometric equations, by definition, rely on standard tree growth patterns and architecture. Application of equations based on trees inside forests may generate biased estimates, as much as $20 \%$ off, suggesting the need to produce equations specific for trees on farms if accurate accounting is desired (Kuyah et al. 2012a).

The requisite tree growth information for allometric equation is best obtained by destructive sampling felling and weighing trees in the field (Brown 1997). Costs and logistics associated with field measurements always limit the number of destructive experiments, the number of trees harvested, the parts of the tree measured and the size of trees harvested. As a result, allometric equations are often based on sample sizes of 30 or fewer trees of relatively small diameters (e.g. less than $30 \mathrm{~cm}$ ) or existing data not specifically collected for the purpose. This is significant because biomass estimates can be skewed if allometric equations (1) were derived from datasets based on smaller diameter trees (2) do not include all tree components such as branches and leaves, and (3) are applied under environmental conditions for which they were not developed (Brown 1997; Kuyah et al. 2012a). Such cost-constrained research decisions define the value and applicability of the generated allometric model.

The predictors included in the allometric model may also introduce error or bias into biomass estimates. Tree diameter (DBH) is the most widely applied predictor of biomass and contained in virtually all allometric equations that are not based solely on remotely-sensed crown area (Gibbs et al. 2007). Height, crown area, and wood density have been reported to be useful supplements for improving the accuracy of biomass equations based on DBH (Chave et al. 2005; Ketterings et al. 2001; Kuyah et al. 2012a). However, these additional measurements can be costly and are prone to errors. Errors arising in the field clearly propagate into misleading biomass estimates for the subject population and subsequent studies that apply existing equations.

The lack of robust and validated information and methods of biomass for trees on farm limits the evaluation of their functional role in the $\mathrm{C}$ cycle and their climate change mitigation potential. Defining optimal biomass estimation procedures and appropriate equations and parameters for robust, consistent, and low-cost quantification are necessary to improve our understanding of trees on farm and the $\mathrm{C}$ cycle. Such information will help rapidly increase the volume and quality of data for trees on farms and is vital for individuals, projects, and communities that may benefit from emerging climate change mitigation opportunities (e.g. Nationally Appropriate Mitigation Actions) and timber markets by growing trees. Here, we identify methodologically and economically efficient biomass sampling procedures to provide robust biomass estimates for agricultural landscapes.

\section{Materials and methods}

\section{Study site}

The study was conducted in three $100 \mathrm{~km}^{2}$ sites along the altitudinal gradient in the Yala River basin in Western Kenya (Lower Yala, Middle Yala and Upper Yala). Each site consists of $10 \times 10 \mathrm{~km}$ blocks, each divided into 16 sub-blocks (clusters, $2.5 \times 2.5 \mathrm{~km}$ ) with 10 plots in each cluster (Vågen et al. 2012). The Lower Yala site is located in Siaya and Kisumu Counties, latitude $0^{\circ} 1^{\prime} \mathrm{S}$; longitude $34^{\circ} 28^{\prime} \mathrm{E}$; the Middle Yala site is located in Vihiga and partly in 
Fig. 1 The location of the three study sites in the Yala River Watershed, Western Kenya

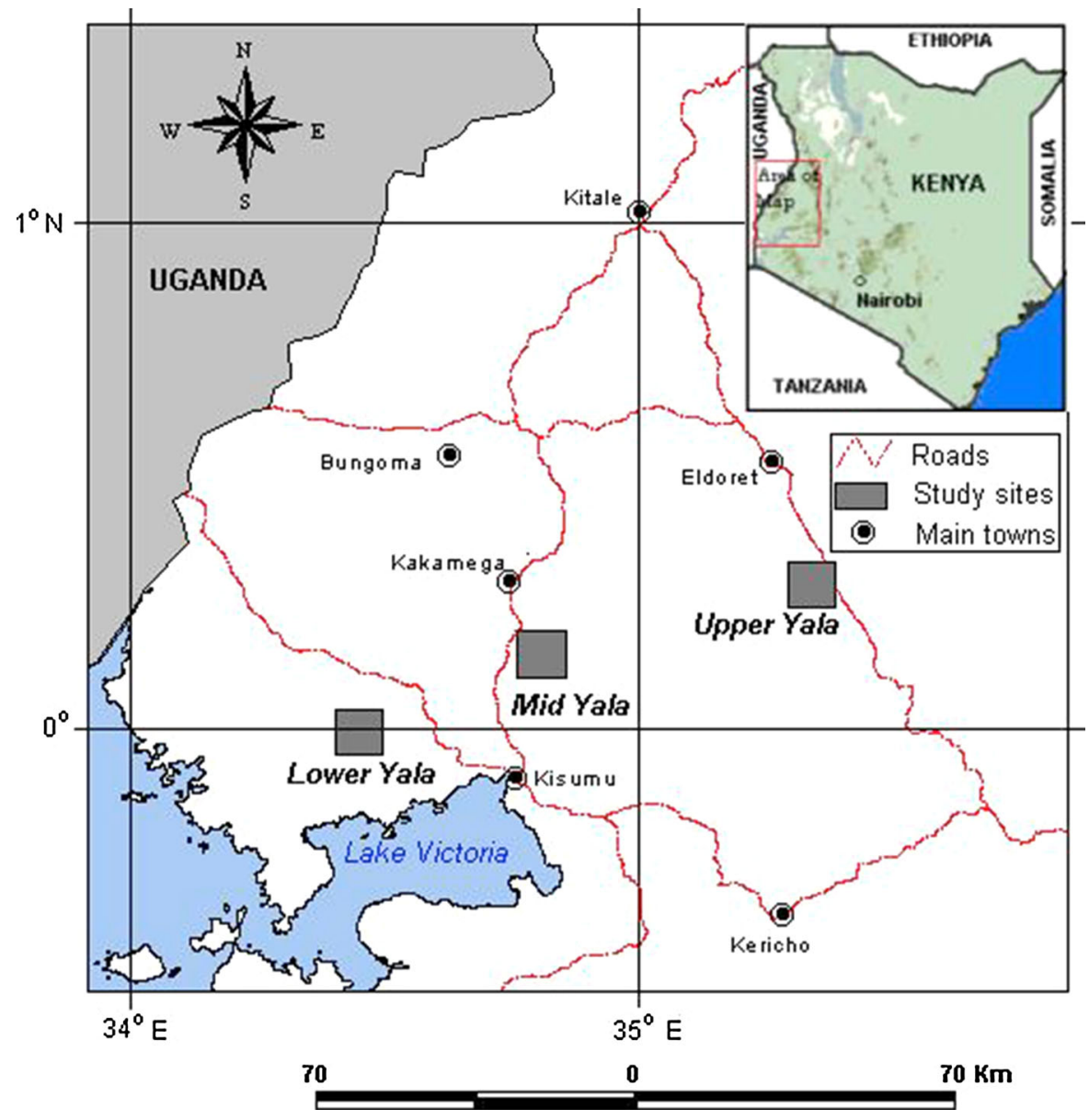

Kakamega Counties, latitude $0^{\circ} 7^{\prime} \mathrm{N}$; longitude $34^{\circ} 49^{\prime} \mathrm{E}$; while the Upper Yala site is located in Uasin Gishu District, $0^{\circ} 17^{\prime} \mathrm{N}$; longitude $35^{\circ} 20^{\prime} \mathrm{E}$. The mean annual rainfall across in the basin ranges between 1,000 and $1,800 \mathrm{~mm}$, received in two seasons. The mean annual temperature is $21.9^{\circ} \mathrm{C}$ in Lower Yala, $20.5{ }^{\circ} \mathrm{C}$ in Middle Yala and $16.7^{\circ} \mathrm{C}$ in Upper Yala. Dominant soil types along the River Yala basin include Acrisols, Ferralsols and Nitisols (Jaetzold et al. 2007). Figure 1 shows the location of the study sites in the River Yala basin, with an altitudinal gradient ranging of $1,200 \mathrm{~m}$ in the Lower Yala to 2,200 $\mathrm{m}$ in Upper Yala.

The three sites cross altitudinal, slope, precipitation, and management gradients-from relatively uniform topography with low precipitation managed at low agricultural intensity to the opposite, high intensity agriculture on slopes receiving more significant rainfall (Boye et al. 2008). Agricultural expansion has reduced forest area and natural vegetation in the region to the point where now woody vegetation exists as part of a complex agricultural mosaic including: individual free standing exotic and naturalized species (Eucalyptus, Acacia mearnsii) near the homestead or intercropped, boundary plantings around fields, and stands of mono-specific and mixed indigenous species e.g. Markhamia lutea (Glenday 2006; Henry et al. 2009).

Data collection

Trees used in the broader data of Kuyah et al. (2012a) were used for this evaluation. The 72 trees selected for destructive sampling $(N=72)$ and 855 trees inventoried for indirect biomass assessment $(N=855)$ were measured in twenty-eight $(30 \times 30 \mathrm{~m}, 0.09$ ha) plots distributed throughout the three sites. The plots were established on 28 of the $160(16 \times 10)$ randomized 
sample points within each of the $10 \times 10 \mathrm{~km}$ sites. A randomized sub-set of these points were used (15\% of all previously existing sampling points in lower Yala, $30 \%$ in the middle Yala and $15 \%$ in the upper Yala, Fig. 1). On each of those sampling points chosen randomly, a $30 \times 30 \mathrm{~m}$ plot was drawn where all trees were inventoried (in situ) in addition to the destructive sampling. Study plots were selected to capture the diversity of tree species occurring in the landscape and trees of the same species at various altitudes. Tree diameter (DBH) ranged from 2.5 to $102 \mathrm{~cm}$ and were categorized into six classes i.e. $<10,10-20,20-30$, $30-40,40-50$, and $>50 \mathrm{~cm}$. Trees felled and measured in each class were selected randomly from an inventory list. When trees of larger DBH could not be found in the plots via the inventory list, we intentionally harvested those outside the pre-selected plots, but within the $(10 \times 10 \mathrm{~km}$ blocks $)$ landscape. Destructive measurements of the 72 trees were the basis of the accuracy and cost analyses when constructing allometric equations. In addition, we inventoried all trees with $\mathrm{DBH} \geq 2.5 \mathrm{~cm}$ within these 28 plots $(N=855)$ and measured DBH, height, crown area and wood density. We used these inventory measurements to estimate landscape level biomass.

\section{Destructive measurements}

Tree diameter $(\mathrm{DBH})$, height, and crown area were measured prior to felling the 72 trees selected for destructive measurements and for the additional 855 trees inventoried. Tree diameter (DBH) was measured $1.3 \mathrm{~m}$ above the ground. When trees growth showed anomalies (e.g. fluting), conventional methods of DBH estimation were used (West 2009). Tree height was measured with a hypsometer and later validated by measuring the length of felled trees. Crown areas were estimated by establishing the crown edge with a clinometer, length $(l)$ and width $(w)$ were measured using orthogonal transects, and crown area was calculated based on the measured diameters assuming an ellipse shape, $c a=\pi \times\left(\frac{1}{2} \times \frac{w}{2}\right)$ (Kuyah et al. 2012b).

Destructively sampled trees were cut as closely to the ground as possible with a chain saw. Branches were detached from the stem and the leaves stripped from the branches. The stem represents the main trunk of the tree from the cut point at the base to the tip. All woody parts arising from the stem were included as branches while the foliage arising from branches was included as leaves. Leaves of species such as acacia and Cupressus lusitanica could not be detached individually from the small branches and were weighed together with smaller branches (less than $1 \mathrm{~cm}$ in diameter) as twigs. Tree components including stems, branches, and leave were cut into weighable sections, when necessary, and their fresh weight determined on the site by balance $(300 \mathrm{~kg}$ with precision of $0.1 \mathrm{~kg}$ ). To account for losses due to the sectioning of components into smaller pieces, we multiplied the wood density of the tree by the volume of the chain saw gap. Leaves were weighed separately from the branches in the field. Subsamples of all components were taken to determine the dry weight to estimate biomass. The fresh weight of subsamples of the tree components was determined using a $3 \pm 0.001 \mathrm{~kg}$ balance. The subsamples were oven dried at $105{ }^{\circ} \mathrm{C}$ for approximately $24 \mathrm{~h}$, until no further changes in weight occurred.

Wood density was determined by coring about $50 \%$ deep into the stem at $1.3 \mathrm{~m}$ using a carpenter's awl and $2.5 \mathrm{~cm}$ bit. The cored material was collected from the hole with a spatula and their fresh weight determined in the field. The width $(w)$ and depth $(d)$ of the core were determined for calculation of the volume $v=\pi \times\left(\frac{w}{2}\right)^{2} \times d$ of the core. Cored samples were dried to a constant weight in a well-ventilated oven at $105{ }^{\circ} \mathrm{C}$ for $24 \mathrm{~h}$. Wood density was then determined as the ratio of the dry weight of the cored material to the volume of the core. Species in the data whose wood density values were not determined during biomass sampling were given wood density values found in the global wood density database (Chave et al. 2009a, b) and African wood density database (Carsan et al. 2012).

\section{Measurement costs}

We calculated the costs associated with tree compensation, labor, chain saw rental and transportation to the sites for individual trees harvested $(N=72)$. Compensation in Kenya Shilling (KES) at the rate of \$USD $=$ KES85 was made for every tree cut depending on the size of the tree. A general range of $<10 \mathrm{~cm}$ trees at \$1-3, 11-20 cm trees at \$3-11, 21-30 cm trees at $\$ 12-35,31-40$ trees at $\$ 35-60,41-50$ trees at 
$\$ 60-95$ and \$105-235 for trees with DBH over $50 \mathrm{~cm}$ was agreed upon after consultation with selected timber dealers in Kisumu, Kakamega and Eldoret. These rates were slightly below the prevailing market price, though it varied across the basin depending on the tree species, the farmers' plan (purpose of planting the tree) and family needs at the moment. Indigenous and fruit tree species attracted over three times the price of regular exotic tree species, disregarding size. Further, damage caused on crops or neighboring trees after felling the selected tree was pre-determined (arbitrarily) prior to felling trees. For every individual tree cut, two Grevillea robusta trees were given out to the farmer to plant. The aggregate cost of seedlings, price of cut tree and payment for damaged constituted the total compensation cost.

Operational costs included local car rental, chain saw rental, fuel for car and saw, and labor multiplied by the number of days per tree. Because a day's transport could facilitate work on several trees depending on size, the cost of transport per tree was calculated as a fraction (\%) of the transport depending on the average number of trees that could be completed in a day. The cost of skilled and casual laborers was calculated by multiplying their daily wage by person's labor days (the fraction of a day or the number of days required to complete sampling a tree of a given diameter). Skilled labor included three field technicians (one who doubled as a driver), and a laboratory technician who received and processed the samples. The cost of equipment and other field related costs, such as sensitization meetings (which include payment to facilitate local leaders and farmers to attend these meetings); consultative meetings with the Kenyan Forest Service were not included. The cost for developing the different allometric equations were based on the cost of sampling trees included in the equation, based on diameter distribution.

Allometric equation by Kuyah et al. (2012a), and Brown (1997) and those built from three sets of data in this study: (1) Equation 1 with 36 small diameter trees only (DBH $2.5-30 \mathrm{~cm}$ ) (2) Equation 2 with 36 large diameter trees (DBH 31-102 cm) and (3) equation with 36 trees with evenly distributed $\mathrm{DBH}$ $(2.5-102 \mathrm{~cm})$ were used to evaluate landscape level biomass predictions. Allometric equations were developed using least squares regression after log transforming of the data. A correction factor (CF) was calculated from the standard error of the estimate of the regression (SEE), $C F=\operatorname{Exp}(S E E / 2)^{2}$ and used to correct for bias introduced by log transformation of the data (Sprugel 1983). These equations were also used to establish the trade-off between accuracy and cost. The equation by Kuyah et al. (2012a) assumes the whole cost of destructively sampling of the 72 trees. No cost is incurred by using tier II approach, where the two equations by Brown (1997) were sourced from the literature. Application of these equations to an inventory of 855 trees measured across the landscape provided variations in biomass estimates depending on the methods applied in measurements, and the choice of allometric equation. The equations were compared using absolute biomass estimates, the mean relative error (MRE), mean square error (MSE), predicted residual sum of squares (PRESS), and Furnival's Index (FI). The mean relative error $(\%)$ was calculated using the formula $M R E=\left(A G B_{\text {Predicted }}-\right.$ $\left.\left.A G B_{\text {Measured }}\right) / A G B_{\text {Measured }}\right) \times 100$. The MSE was calculated as the average of the squared errors. PRESS was calculated as the sums of squares of the prediction residuals while FI was calculated as a product of the square root of mean square error and the inverse of the geometric mean of the derivative of the natural logarithms of AGB, $(\ln (\mathrm{AGB}))$ :

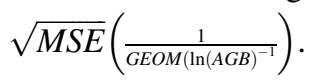

\section{Results and discussion}

We found that inclusion of height, wood density or crown area in biomass equation changed biomass estimates by a trivial amount, less than $1.2 \mathrm{Mg}$ or $1.3 \%$ of total biomass, from those obtained by using the diameter alone equation (Table 1). The equation with $\mathrm{DBH}$ and wood density was marginally better than all the others in describing the current data i.e. has smaller indices of model fit and predictive ability (Table 1). Height on the other hand was not significant and had large standard error, indicating that inclusion of height does not increase model predictive ability of diameter based equations. This suggests that allometric equations relying on DBH alone create relatively robust biomass estimates for trees on farm and the additional resources (time, personnel and equipment) necessary to measure height and crown area do not compensate for the small increase in accuracy of the biomass estimate. Furthermore, measurements of 
Table 1 Coefficients of biomass estimation models ( $\mathrm{a}, \mathrm{b}$ and $\mathrm{c}$ ) and biomass estimates determined from equation that includes different parameters measured

\begin{tabular}{|c|c|c|c|c|c|c|c|c|c|c|}
\hline \multirow[t]{2}{*}{ Parameters } & \multicolumn{3}{|c|}{ Allometric coefficients } & \multirow{2}{*}{$\begin{array}{l}\text { Estimate } \\
\text { (Mg/ha) }\end{array}$} & \multirow[t]{2}{*}{ Adj. $R^{2}$} & \multirow[t]{2}{*}{ MRE } & \multirow[t]{2}{*}{ MSE } & \multirow{2}{*}{$\begin{array}{l}\text { Furnivall's } \\
\text { Index }\end{array}$} & \multirow[t]{2}{*}{ PRESS } & \multirow[t]{2}{*}{ AIC } \\
\hline & A & B & $\mathrm{C}$ & & & & & & & \\
\hline DBH alone & 0.091 & 2.472 & & 36.4 & $0.977^{*}$ & 7.8 & 0.070 & 1.351 & 5.229 & 16.603 \\
\hline DBH and height & 0.092 & 2.488 & -0.028 & 35.9 & 0.977 & 7.0 & 0.071 & 1.360 & 5.358 & 18.603 \\
\hline DBH and wood density & 0.225 & 2.341 & 0.730 & 36.5 & 0.984 & 4.8 & 0.049 & 1.132 & 3.769 & -7.890 \\
\hline DBH and crown area & 0.107 & 2.318 & 0.101 & 36.3 & 0.978 & 6.3 & 0.067 & 1.320 & 5.068 & 14.114 \\
\hline
\end{tabular}

Indices of predictive ability of the models (MRE mean relative error) and model fit (MSE mean square error, Furnival's index PRESS predicted residual sum of squares, and AIC Akaike information criterion) are provided. Other than the model build with DBH, the Adj. $R^{2}$ (adjusted $\mathrm{R}^{2}$ ) refers to the coefficient of multiple correlation

* indicates that the value is $\mathrm{R}^{2}$ and not adjusted $\mathrm{R}^{2}$

Table 2 The range of plant characteristics (by species) measured on trees harvested in western Kenya for development of allometric equations

\begin{tabular}{|c|c|c|c|c|c|c|c|c|c|c|c|c|c|}
\hline \multirow[t]{2}{*}{ Species } & \multirow{2}{*}{$\begin{array}{l}\text { Number of } \\
\text { trees }\end{array}$} & \multicolumn{3}{|c|}{$\mathrm{DBH}(\mathrm{cm})$} & \multicolumn{3}{|c|}{ Height $(\mathrm{m})$} & \multicolumn{3}{|c|}{ Crown area $\left(\mathrm{m}^{2}\right)$} & \multicolumn{3}{|c|}{ Aboveground biomass $(\mathrm{kg})$} \\
\hline & & Mean & Min. & Max. & Mean & Min. & Max. & Mean & Min. & Max. & Mean & Min. & Max. \\
\hline Acacia mearnsii & 8 & 25.3 & 10.1 & 39.4 & 11.7 & 6.4 & 18.9 & 35.2 & 7.0 & 71.6 & 436.6 & 36.8 & 875.6 \\
\hline Combretum molle & 1 & 39.8 & 39.8 & & 13.9 & 13.9 & & 49.9 & 49.9 & & 669.6 & 669.6 & \\
\hline Cupressus lusitanica & 3 & 17.4 & 6.8 & 25.2 & 9.2 & 5.8 & 12.7 & 24.5 & 8.5 & 33.1 & 113.6 & 10.0 & 201.5 \\
\hline Eucalyptus camaldulensis & 20 & 42.9 & 8.1 & 96.0 & 26.7 & 9.3 & 44.5 & 65.4 & 5.6 & 209.3 & 1365.7 & 11.9 & 7427.9 \\
\hline Eucalyptus grandis & 6 & 12.4 & 6.6 & 24.0 & 11.2 & 6.6 & 15.1 & 8.9 & 1.5 & 17.7 & 50.5 & 7.6 & 159.0 \\
\hline Eucalyptus saligna & 5 & 15.0 & 5.3 & 31.2 & 13.9 & 6.6 & 23.3 & 11.8 & 2.8 & 26.4 & 172.9 & 5.8 & 492.9 \\
\hline Ficus $s p$ & 1 & 73.0 & 73.0 & & 14.4 & 14.4 & & 73.9 & 73.9 & & 1858.1 & 1858.1 & \\
\hline Grevillea robusta & 5 & 58.4 & 37.0 & 85.8 & 20.0 & 15.4 & 24.7 & 152.0 & 59.2 & 229.6 & 2708.2 & 658.4 & 5705.2 \\
\hline Jacaranda mimosifolia & 2 & 67.8 & 50.0 & 85.5 & 20.8 & 19.6 & 22.0 & 136.2 & 82.9 & 189.5 & 3298.4 & 1167.6 & 5429.2 \\
\hline Mangifera indica & 6 & 41.3 & 21.0 & 78.0 & 8.6 & 5.5 & 13.5 & 68.0 & 25.5 & 150.2 & 1219.2 & 210.1 & 3097.4 \\
\hline Markhamia lutea & 7 & 14.2 & 3.2 & 33.4 & 9.1 & 4.2 & 13.8 & 9.9 & 0.4 & 23.8 & 75.4 & 2.8 & 263.5 \\
\hline Persia americana & 2 & 16.0 & 12.2 & 19.8 & 8.2 & 6.9 & 9.6 & 17.2 & 12.1 & 22.3 & 79.2 & 42.7 & 115.6 \\
\hline Spathodea campanulata & 1 & 8.2 & 8.2 & & 6.0 & 6.0 & & 4.9 & 4.9 & & 7.7 & 7.7 & \\
\hline Syzygium cordatum & 2 & 92.8 & 83.4 & 102.2 & 36.0 & 35.3 & 36.6 & 236.4 & 186.2 & 286.5 & 10354.5 & 8481.9 & 12227.2 \\
\hline Syzygium cuminii & 2 & 37.5 & 34.0 & 41.0 & 13.0 & 12.0 & 13.9 & 40.7 & 36.1 & 45.2 & 548.7 & 406.6 & 690.8 \\
\hline $\begin{array}{l}\text { Trilepisium } \\
\quad \text { madacascariensis }\end{array}$ & 1 & 60.0 & 60.0 & 60.0 & 35.4 & 35.4 & 35.4 & & & & 1675.7 & 1675.7 & 1675.7 \\
\hline
\end{tabular}

height and crown area can be subject to operator error. Hypsometer readings can be hindered when measuring total tree height on a steep slope or in a closed canopy. Likewise, crown area measurements are subject to operator decisions of where the crown edge lies and can be impacted by overlapping trees. Thus, we conclude that the $\sim 1.3 \%$ of total biomass difference between the various parameters is likely fungible given the concerns over accuracy and the additional time it takes to measure height and crown area. We conclude that DBH alone is a robust proxy for trees in this landscape, particularly because DBH only equations are simpler, less costly and provide more effective predictions (Sileshi 2014). The relevance for other landscapes with other species, tree configuration and environmental conditions will need to be tested further but based on our data DBH seems to be a promising low-cost proxy for ground-based inventories.

The range of plant characteristics measured on the trees by species and the characteristics of individual trees harvested in each of the sites, including management influence are presented in Table 2 and appendix 1 (in supplementary material), respectively. 
A scatter plot of aboveground biomass against DBH for the 72 trees harvested is shown in Fig. 2. Irregular forms of trees with deep indentations can lead to overestimation of biometric attributes (Nogueira et al. 2006) and thus confound the use of DBH alone. However, few fluted tree were encountered in the farms surveyed. For one harvested tree, the DBH measured along the flutes was greater, $73 \mathrm{~cm}$ compared to the one measured conventionally, $60 \mathrm{~cm}$. DBH measurements from irregular shaped stems significantly influence biomass estimates for a particular tree when incorrectly measured (Nogueira et al. 2006). This disparity is shown in the substantial difference in biomass, $2.9 \mathrm{Mg}$ from conventionally measured DBH (a value close to the actual biomass, $3.1 \mathrm{Mg}$ ) and $4.7 \mathrm{Mg}$ from DBH measured along the flutes, when predicted using the equation by Kuyah et al. (2012a). Despite the potential errors, fluted trees occur infrequently in this landscape and on farms as

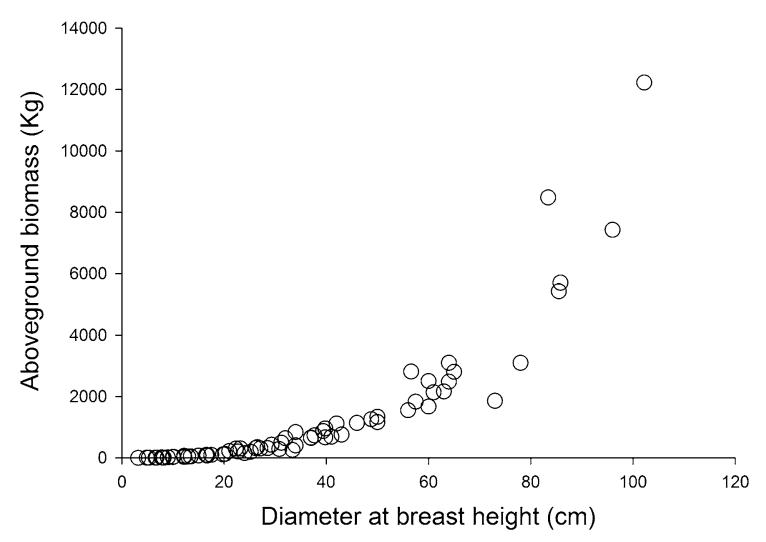

Fig. 2 A scatter plot of aboveground biomass against diameter at breast height for the 72 trees harvested in western Kenya most trees are managed and planted trees rarely show flutes. Consistent estimations are therefore expected for trees in agricultural lands.

Greater deviations in the mean relative error, MRE (from estimates by the $\mathrm{DBH}$ alone) were found in biomass estimates of smaller diameter trees, while greater differences in absolute values occurred in estimates of larger diameter trees. This underscores the difficulty in accurately estimating the biomass of small trees due to the large biomass variability. Small (immature) trees may not yet have a well-developed root system, which renders their architecture more vulnerable to (or at least dependent on) edaphic factors such as nutrient and water supply. Trees typically overcome such constrains as they grow. By contrast, the variability of mature trees is caused by management practices like selective harvesting of stems, e.g. for poles, lopping of branches to provide fuel-wood, pollarding to reduce light competition with crops, and pruning (Appendix 1 in supplementary material). Such management interventions alter biomass without directly affecting DBH. Given the estimation challenges presented by trees of various age and size and the relative accuracy and cost data (Table 3), we recommend that studies with limited budgets aim to harvest a well distribution sample across the relevant age/DBH classes (equation 3, $A G B=0.091 \times$ $\left.D B H^{2.472}\right)$.

Trade-offs between investment and accuracy were demonstrated by constructing equations from limited samples and applying them to the entire sample set (Table 3). Application of the resulting equations to trees of larger diameter than the ones used in construction of the equation yielded poor estimates,

Table 3 The cost of developing biomass equations with trees of different sizes, the respective mean relative error (MRE), and the landscape level biomass estimates

\begin{tabular}{|c|c|c|c|c|c|c|}
\hline Allometric equation & Model & $\begin{array}{l}\text { Number } \\
\text { of trees }\end{array}$ & $\mathrm{DBH}(\mathrm{cm})$ & Cost $(\$)$ & $\operatorname{MRE}(\%)$ & $\begin{array}{l}\text { Estimate } \\
(\mathrm{Mg} / \mathrm{ha})\end{array}$ \\
\hline Equation 1 & $Y=\operatorname{Exp}\{-2.399+2.4602 \times \ln (D B H)\}$ & 36 & $2.5-30$ & 2424 & 6.3 & 35.2 \\
\hline Equation 2 & $Y=\operatorname{Exp}\{-2.904+2.5880 \times \ln (D B H)\}$ & 36 & $31-102$ & 9430 & 8.2 & 35.7 \\
\hline Equation 3 & $Y=\operatorname{Exp}\{-2.405+2.4672 \times \ln (D B H)\}$ & 36 & $2.5-102$ & 5737 & 7.2 & 35.8 \\
\hline Kuyah et al. (2012a) & $Y=\operatorname{Exp}\{-2.4033+2.4718 \times \ln (D B H)\}$ & 72 & $2.5-102$ & 11853 & 7.8 & 36.4 \\
\hline Brown (1997) (dry forest) & $Y=\operatorname{Exp}\{-1.996+2.32 \times \ln (D B H)\}$ & 28 & $5-40$ & & 1.2 & 31.7 \\
\hline Brown (1997) (moist forest) & $Y=\operatorname{Exp}\{-2.134+2.53 \times \ln (D B H)\}$ & & & & 59 & 58.3 \\
\hline
\end{tabular}




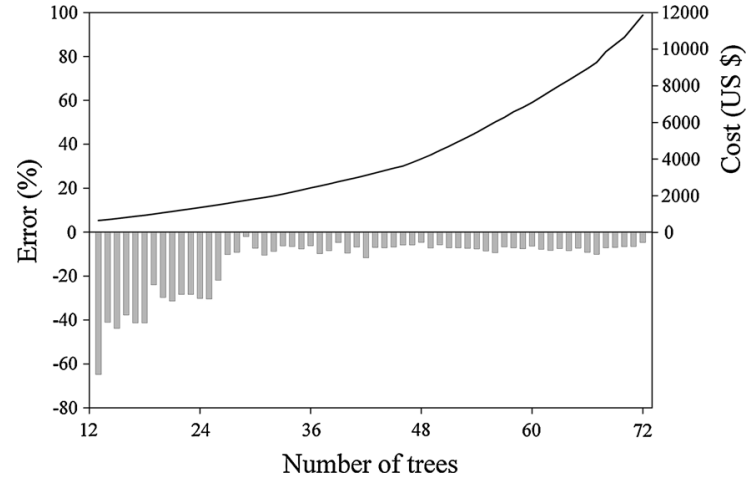

Fig. 3 Accuracy versus financial implication: the mean relative error (error \%) of equations derived from a limited number of trees but applied to all 72 trees and the cost of sampling trees of different sizes. The trees are ordered by increasing diameter at breast height

although the prediction equation error decreased substantially above a sample size of 30 trees. While the cost of sampling large trees and their scarcity in the landscape may justify their absence from calibration dataset for many equations, our study is consistent with the observation that equations that lack input from large diameter classes cannot be used to accurately estimate the biomass held in large trees (Brown 1997). Disregarding equipment costs assuming they are available, our equations reveal that 30 trees may represent the minimum sample size necessary to reduce error to below $10 \%$ (Fig. 3). The costs related to compensation due to damages and inaccessibility to the plots can be mitigated by planning the study after the cropping season and avoiding extreme rainy season. Thus the cost of sampling increased as the number and size of trees increased, as a function of tree access, labor, and owner compensation cost.

\section{Conclusion}

The prevailing constraints of available biomass data and the limitations of existing allometric equations creates conditions where little can be said about either the importance or opportunities for $\mathrm{C}$ sequestration with trees on farm. We identified economically and technically efficient measurement strategies that can inform future destructive measurements of trees on farms to strike the appropriate balance between accuracy and cost necessary to provide robust estimates of biomass in agricultural systems.
Acknowledgments The authors would like to thank ICRAF technical staff in Kisumu for helping with data collection, and the farmers in western Kenya who permitted us to work in their fields. We thank GEF, UNEP, WWF, Michigan State University, University of Maryland, Colorado State University, and ICRAF for supporting data collection as part of the Carbon Benefits Project. This additional analysis was funded by the Climate Change, Agriculture, and Food Security Consortium Research Program of the Consultative Group of International Agricultural Research as part of the Standard Assessment of Mitigation Potential and Livelihoods in Smallholder Systems (SAMPLES) and Mitigation of Climate Change in Agriculture (MICCA) programmes.

Open Access This article is distributed under the terms of the Creative Commons Attribution License which permits any use, distribution, and reproduction in any medium, provided the original author(s) and the source are credited.

\section{References}

Boye A, Verchot L, Zomer R (2008) Baseline report: Yala and Nzoia river basins. Western Kenya integrated ecosystem management project. World Agroforestry Centre (ICRAF), Nairobi

Brown S (1997) Estimating biomass and biomass change of tropical forests: a primer. (FAO Forestry Paper-134). Food and Agriculture Organization of the United Nations (FAO), Rome

Carsan S, Orwa C, Harwood C, Kindt R, Stroebel A, Neufeldt H, Jamnadass R (2012) African wood density database. World Agroforestry Centre. Accessed 22 Oct 2013

Chave J, Andalo C, Brown S, Cairns MA, Chambers JQ, Eamus D, Fölster H, Fromard F, Higuchi N, Kira T, Lescure J-P, Nelson BW, Ogawa H, Puig H, Riéra B, Yamakura T (2005) Tree allometry and improved estimation of carbon stocks and balance in tropical forests. Oecologia 145(1):87-99

Chave J, Coomes D, Jansen S, Lewis SL, Swenson NG, Zanne AE (2009a) Towards a worldwide wood economics spectrum. Ecol Lett 12(4):351-366

Chave J, Coomes DA, Jansen S, Lewis SL, Swenson NG, Zanne AE (2009b) Data from: towards a worldwide wood economics spectrum. Dryad Data Repos. doi:10.5061/dryad. 234

de Foresta H, Somarriba E, Temu A, Boulanger D, Feuilly H, Gauthier M (2013) Towards the Assessment of Trees Outside Forests. Resources Assessment Working Paper 183. FAO Rome

Gibbs HK, Brown S, Niles JO, Foley JA (2007) Monitoring and estimating tropical forest carbon stocks: making REDD a reality. Environ Res Lett 2:13

Glenday J (2006) Carbon storage and emmision offset potential in an East African tropical rainforest. For Ecol Manag 235:72-83

Harja D, Vincent Gg, Mulia R, Van Noordwijk M (2012) Tree shape plasticity in relation to crown exposure. Trees 26:1275-1285 
Henry M, Tittonell P, Manlay RJ, Bernoux M, Albrecht A, Vanlauwe B (2009) Biodiversity, carbon stocks and sequestration potential in aboveground biomass in smallholder farming systems of western Kenya. Agric Ecosyst Environ 129(1-3):238-252

IPCC (2007) Climate change 2007: The physical science basis. Contribution of working group I to the fourth assessment report of the intergovernmental panel on climate change. Cambridge University Press, Cambridge

Jaetzold R, Schmidt H, Hornetz B, Shisanya C (2007) Farm Management Handbook of Kenya vol. 2-Natural conditions and farm management information. Part A West Kenya, Subpart A1 Western Province. 2nd Edition. Ministry of Agriculture, Kenya, in Cooperation with the German Agency for Technical Cooperation (GTZ), Nairobi, Kenya

Ketterings QM, Coe R, Van Noordwijk M, Ambagau Y, Palm CA (2001) Reducing uncertainty in the use of allometric biomass equations for predicting above-ground tree biomass in mixed secondary forests. For Ecol Manag 146:199-209

Kuyah S, Dietz J, Muthuria C, Jamnadassa R, Mwangi P, Coe R, Neufeldt H (2012a) Allometric equations for estimating biomass in agricultural landscapes: I. aboveground biomass. Agric Ecosyst Environ 158:216-224

Kuyah S, Muthuri C, Jamnadass R, Mwangi P, Neufeldt H, Dietz J (2012b) Crown area allometries for estimation of aboveground tree biomass in agricultural landscapes of western Kenya. Agrofor Syst 86(2):267-277

Lal R (2004) Soil carbon sequestration to mitigate climate change. Geoderma 123(1-2):1-22
Nair PKR, Nair VD (2014) 'Solid-fluid-gas': the state of knowledge on carbon-sequestration potential of agroforestry systems in Africa. Curr Opin Environ Sustain 6:22-27

Nogueira EM, Nelson BW, Fearnside PM (2006) Volume and biomass of trees in central Amazonia: influence of irregularly shaped and hollow trunks. For Ecol Manag 227:14-21

Sileshi GW (2014) A critical review of forest biomass estimation models, common mistakes and corrective measures. For Ecol Manag 329:237-254

Sprugel DG (1983) Correcting bias in log transformed allometric equations. Ecology 64(1):209-210

Vågen T-G, Davey FA, Shepherd KD (2012) Land health surveillance: mapping soil carbon in Kenyan rangelands. In: Nair PKR, Garrity D (eds) Agroforestry: the future of global land use, advances in agroforestry, vol 9. Springer Science+Business Media, Dordrecht, pp 455-462

Verchot LV, Noordwijk M, Kandji S, Tomich T, Ong C, Albrecht A, Mackensen J, Bantilan C, Anupama KV, Palm C (2007) Climate change: linking adaptation and mitigation through agroforestry. Mitig Adapt Strat Glob Change 12(5):901-918

West PW (2009) Tree and forest measurement, 2nd edn. Springer, Heidelberg

Zomer RJ, Trabucco A, Coe R, Place F (2009) Trees on farm: analysis of global extent and geographical patterns of agroforestry. ICRAF Working Paper no. 89. Nairobi, Kenya: World Agroforestry Centre 